\title{
Taking Snapshots, Living the Picture: The Kodak Company's Making of Photographic Biography
}

\section{Gil Pasternake}

Pasternak, Gil, "Taking Snapshots, Living the Picture: The Kodak Company's Making of Photographic Biography," Life Writing 12(4), Special Issue: Self-regarding: Looking at Photos in Life Writing, 2015: 431- 446

\begin{abstract}
In this article I explore how George Eastman and the Eastman Kodak Company encouraged early twentieth-century camera users to think of snapshots as pictorial biographies. Analysing a wide selection of articles from the Kodakery, one of Kodak's most popular magazines in the first half of the twentieth century, I demonstrate that the company endeavoured to secure its prominence in the photographic market by encouraging members of the public to integrate picture-taking into everyday life, and regard photographs as self-contained repositories of biographical details. To this end, Kodak framed the speedy pace of life that characterised the practice of being in the industrial world as a reality that allegedly weakened the human eye and mind's ability to process the experience of life itself. Introducing the idea of the camera and picture-taking as the ultimate cures for this purported human deficiency, Kodak provided camera users with advice that helped to cement an understanding of photographs as surrogates of both the changing human body and individual subjects' experiences in time and space. As in popular culture, and sometimes also in academia, photographs are still widely regarded as pictorial biographies, I argue that considering the popular photographic industry's role in shaping photographic practices and photographs' perceived meanings can help clarify the relationship between photography and life-writing.
\end{abstract}

Keywords: biography, Kodak, Kodakery, photograph albums, snapshots, story-telling pictures

When George Eastman released the handheld, easy-to-use Kodak camera in 1888, he stated that the photographs the Kodak can take 'may be made to furnish a pictorial history of life as it is lived by the owner, that will grow more valuable every day that passes' (qtd. in Gernsheim 414). Eastman sold the Kodak camera ready-to-use, preloaded with a roll of negative stripping-paper film of 100 exposures. When the last of the pictures had been taken, the Kodak user would post the camera to the Eastman factory in Rochester, where the film was processed, prints were made, and a new roll of film was inserted into the camera. Five to ten days later the customer would receive the Kodak back, ready to use, alongside the negatives and prints. By simplifying the process of image taking, and in founding the developing and printing industry, technically Eastman made it possible for virtually anyone to produce photographs. In doing so, he planted the seeds for the integration of photography into the practice of everyday life (Coe 83).

Guidebooks about popular photography published in recent years evidence that the belief that photographs can impart knowledge about the lived experiences and characters of those imprisoned within the photographic image is widespread. ${ }^{1}$ Furthermore, the question of the degree to which photographs can provide one with information about their subjects' lives and personalities has occupied numerous scholars in a wide range of academic disciplines. Indeed, scholarly literature often treats photographs with caution, as past occurrences' representational 
constructions that may or may not provide sufficient knowledge about the actualities they stand for. As such, scholars who interrogate the relationship between photography and life writing tend to consider photographs' sitters, viewers, users, and producers as the subjective agencies shaping photographic images' contents and meanings- separately or collaboratively. ${ }^{2}$ But, whereas the volume of this literature suggests that the assumption about photographs' ability to function as biographical records has underpinned individual subjects' relationships with photographs, Elizabeth Siegel's rigorous study of popular photographic practices in Victorian America is one example of a select body of research revealing that this has not been the case throughout the history of photography.

For much of the history of photography in nineteenth-century American popular culture, photographs were made in studio settings, and perceived as capable of very little more than recording the physical features of those they captured (Siegel 87). At best, they served their collectors as reminders of loved ones and prominent sociocultural figures. Because both sitters and their viewers were contemporaneous with one another, photographs were seen as means to maintain their subjects' likenesses in the present, with the purpose of admiring their familiar personalities in the future, but not as independent time or space capsules, let alone as autonomous intelligible representations of inner qualities (145-8). Rather than communicating to their audience information about the past, photographs themselves functioned to connect the present moments they were showing with the present moments of their viewing.

One aspect in the study of the interrelationship between photography and life writing that has received only sparse attention from scholars is the role that the Eastman Kodak Company (hereafter Kodak) - that George Eastman established in 1892-played in inciting 'photography natives' to regard photographs as synonymous with biography. ${ }^{3}$ Launching the Kodak camera and its accompanying developing and printing services in 1888, Eastman separated the act of photographing from the knowledge of turning exposures into pictures. In so doing, he established a new industry that inaugurated the non-professional photographic market, and spawned snapshot photography - the practice of picture taking involving no professional, artistic or aesthetic aspiration. Owing to its fairly high price of 25 US dollars, the 1888 Kodak camera mainly enjoyed demand by the financially-secure upper-middle classes (Coe 83-5). But, in February 1900 Kodak expanded photography's non-professional market by launching the box Brownie camera. Similar to the 1888 camera, operating the Brownie required no specialist knowledge or expertise. In fact, its packaging introduced the Brownie as a toy for children. Unlike the 1888 camera, however, the Brownie was manufactured from cheap materials, allowing Kodak to sell it for only one US dollar. The attractive price made photography affordable for a larger North American and European market. And throughout the early twentieth century, Eastman and Kodak continued developing new cheap-range products, rendering photography a popular practice for nearly anyone who had the money to spare (Coe 89-98).

Most notably, in the first half of the twentieth century Kodak printed and distributed a large set of magazines, newspapers, books and trade circulars in which the company's employees as well as independent authors shared tips, advice and good practice. In particular the editors of these magazines repeatedly invited customers — or 'camerists' as they were called — to submit for publication their photographs as well as queries and stories about their photographic experiences. This served to normalise the practice of sharing, discussing and exchanging photographs taken privately, away from the long-standing standardising confines of the commercial photography studio. ${ }^{4}$ In return, those who partook in the production of snapshots became absorbed in a meshwork in which implicit and explicit ideas about photography travelled widely (King 10; Slater 'Consuming' 57; Slater 'Marketing' 290). 
To fully grasp how Kodak helped link the perception of photographs at large to the concept of biography, it is necessary to distinguish between the amorphous class of 'snapshooters' and other categories of camera users, such as amateur, fine art, and professional photographers. Such categories denote the use of photography by relatively small groups of individual subjects either as a hobby or a way of life. Conversely, through the work carried out by Eastman and Kodak, since the early twentieth century snapshooters have constituted the largest segment of the camera consumers' market as well as the largest cohort of photographic image producers. Snapshooters were dependent on photographic manufacturers for cameras and film processing services for most of the first three quarters of the twentieth century, which guaranteed their exposure to photographic marketing materials. As the leading photographic supplier in America and Europe throughout the first half of the twentieth century, Kodak had a profound influence in shaping the ideas about photography that were circulating among snapshooters (King 10; Slater 'Consuming' 57; Slater 'Marketing' 290). The emergence of social documentary photography, photojournalism, and perhaps even the use of photography by social scientists may constitute some of the histories that have tacitly framed photographs as repositories of knowledge about the nature of human life in the past. But, the camera's ability to produce visually based biographical accounts was an explicit idea that Kodak began propagating in 1907, not least by the marketing slogan 'Let Kodak Keep the Story'. And as Risto Sarvas and David Frohlich explain, because no ordinary person had any domestic product similar to the camera before Kodak rendered photography an easy and affordable popular practice, ' $[\mathrm{t}$ ] he way in which Kodak introduced its technology to the public almost dictated the use and meanings of that technology' (55).

Nancy Martha West has already interrogated how specifically self-contained Kodak advertisements stimulated camerists to take pictures in ways that would help them 'apprehend their experiences and memories as objects of nostalgia' (1). However, in this essay I turn my attention to the articles, stories and photographs that Kodak featured in one of its most popular periodicals in the first half of the twentieth century, Kodakery: A Magazine for Amateur Photographers. ${ }^{5}$ Although the magazine's title suggests the Kodakery was aimed at photography enthusiasts, its contents ranged from technical advice for aspiring photographers to tips for the ordinary snapshooter. Likewise, Kodak provided a free one-year subscription to anyone who purchased either of the cameras it manufactured, thereby ensuring the Kodakery's popularity among professional and non-professional camerists alike. ${ }^{6}$ By analysing the ideas and practical advice that Kodak promoted in the magazine, I will attend to the ways in which the Kodakery sponsored an understanding of photographs as credible, independent and intelligible biographical accounts. The visual and material results of the photographic practices that the Kodakery advocated remain omnipresent in late twentieth and early twenty-first century domestic photographic collections, further shaping their viewers' perceptions of photography at large in association with its alleged biographical properties (Musello; Sarvas and Frohlich 103-37; Slater 'Domestic').

\section{Visual Processing Disorder}

Kodak began publishing the Kodakery in September 1913, when its most profitable arm was earned by catering to photography's non-professional market. Distributed on a monthly basis, primarily in the US and Canada until 1932, the magazine featured articles, stories, photographic images and advertisements for new Kodak products, with a view to helping camerists improve their photographs ('Because this is the First Number' 3). Whereas the Kodakery encouraged 
readers to submit their own photographs for publication as examples of good practice, to qualify as such, the readers' photographs needed 'to prove of interest even to those who are not acquainted with the people, the incident, or the scene portrayed' ('To Our Readers' 25). To clarify what makes a picture interesting, the Kodakery editors listed a specific set of conditions:

To be of general interest a picture must usually contain some principal object, to which the eye is irresistibly drawn [...] Pictures of people may be technically perfect and yet their pictorial value may be wholly destroyed by the subjects informing all observers, by their attitude, that they are posing for a picture [...] Well composed pictures that portray action always compel attention. (25)

As this example shows, although articles and photographs published in the Kodakery were intended to enrich the readers' photographic knowledge and cement its understanding, the details they conveyed were presented to the camerist as a means to an end. Their aim was to increase photographic proficiency so that it could be put into the practice of taking engagingrather than merely technically competent-photographs.

In addition to encouraging its readers to take enticing photographs, the Kodakery inspired them to become frequent and prolific snapshooters. With the aim of influencing them to integrate photography into their daily routines, the Kodakery described experiential problems that allegedly the camera could help resolve. In July 1915, for example, the Kodakery opened with an article entitled 'Musings of the Kodak Philosopher', in which its author asserted that, 'We live in retrospect-on the enjoyments of yesterday' (3). Technological progress, the author claimed, had presented people with new opportunities to see more of the world around them, and in ways that had not been possible in the past. However, the author added that consequently the world was changing at an accelerated pace, making it more difficult to register and retain passing impressions in one's mind. 'The motor car', explained the 'Kodak philosopher', 'whirls us out into the great out-of-doors, where charms of landscape unfold in panoramic confusion, and scenes dissolve as quickly as they form. The aeroplane takes us aloft, where our perspective is changed entirely' (3-4). In this rapidly changing world, the article argued, individual subjects cannot be familiar with the reality underpinning their own lives unless they possess the capability to view and process its fading present. The author thus introduced the idea of the camera as the safest means to register the present instantaneously and accurately. Kodak cameras, the 'Kodak philosopher' claimed, make 'the present ours, and [preserve] the past to us and to our descendants for all the future' (5).

Portraying the human eye and brain as unable to process speedily enough the information with which they are presented owing to the frantically changing nature of reality in the developing industrial world helped Kodak frame the depiction of ordinary occurrences as a matter of necessity. 'TT]he important events of life are not by any means always the sort that seem momentous at the time', wrote one author in the Kodakery of October 1923 ('The School Bell' 4). 'Simple moments', the article continued explaining, 'are often wonderfully significant as we look back upon them', because ' $[t]$ hey make moments live again $[\ldots]$ They give us back the past $[\ldots]$ so that we get a sort of special interest on the investment of living' (4). Moreover, in the November 1915 issue of Kodakery, one author suggested that, without a camera in hand, readers could not even perceive what they actually look like ('Picture Records-True to Life' 6). At the core of this claim was the argument that, 'to know what you look like to others, you must see yourself as others see you' (6). Aiming to achieve this by examining one's self in a mirror, for instance, is not sufficient according to the author, because the more self-conscious people are, the less they resemble their true appearance. But Kodak also had the answer to this problem: 
'There is a way', explained the author, 'and only one way, that you can see your outward self as others see you. This is by examining the photographs of yourself that were made when you were unaware of the making' (6). Pictures of this type, 'taken when you were your natural unposed self, represent you exactly as you appeared' (6). Foregrounding the notion that the activities one performs affect one's appearance, the author suggested that life itself presents individuals with different situations that govern their expressions and attitudes. And it is precisely for this reason that the act of photographing must persist. Failing to secure the constant presence of cameras around them, individuals living in the industrial world would not only lose their ability to adjust to life in this new reality, but they would not even be able to know what they truly look like. Therefore, the author concluded the article by stating that, 'one of the chief missions of the camera in the home should be to serve as a graphic recorder of the home life, chronicling the many changes man and time are ever making' (6).

An examination of the Kodakery shows that it primarily promoted the production of photographs to chronicle the experience of life. The abundant number of pictures each issue featured and the majority of articles published throughout the magazine's lifespan guided readers to seize every opportunity to uphold visual records, significant as well as ordinary, of themselves, their families, friends, and their surrounding environments. Such materials portrayed cameras and photographs as the definitive cures for the inability of human cognition and sight to fully grasp the fleeting and rapidly-transforming nature of life in the industrial world. On the one hand, Kodak constructed memory loss and unfamiliarity with one's self as the human condition in the early twentieth century. On the other, it portrayed photographs as accurate time capsules that store the camerists' lived experiences. The Kodakery presented any subject and every moment as occasions that had to be photographed if one were to adjust successfully to life in the advancing world. Undocumented lives did not only run the risk of disappearing into oblivion, but of being omitted from the experience of life itself.

With such pseudo-scientific narratives Kodak defined the camera as an autonomous agent, a third-party unbiased observer immunised to the camerist's desires. The camera's supposed objective, mechanical perspective had already been theorised in the nineteenth century, but Kodak reframed this idea in the early twentieth century by suggesting photography could do more than just capture and record objective visual images. Rather, it could offer an external perspective of camerists' lives, and would allow no one to construct representations of experience or the self.

\section{Reality in Action}

The capacity to retain the actual stuff of life underpinned a significant portion of the articles published in the Kodakery between 1913 and 1932. However, as the majority of individual subjects in the early twentieth century were still mainly familiar with professionally made photographic portraits whose subjects appeared static and uniform in their facial expressions, Kodak included in the Kodakery of July 1922 an article that challenged camerists' traditional understanding of photography once more. It opened by asserting that people take great interest in stories, specifically favouring and remembering narratives that tell them 'about the things that men and women and boys and girls have done and are doing' ('Story Telling Pictures' 1922 2). Pictures capable of circulating such stories always draw attention, claimed the article, because they hold universal appeal. Other articles appeared in the Kodakery to encourage readers to stop pointing their cameras at static scenes, and start to capture everyday life activities, no matter how 
prosaic. What makes the article of July 1922 stand out is the author's revelation that, 'only a small percentage of the pictures that are sent to us for criticism are story telling pictures' (2-4). The Kodakery defined a story-telling picture as one taken 'when the subject is engaged in some routine occupation, with the attention concentrated on that occupation and not on thoughts of "looking pleasant"“ ('Story-Telling Pictures' 1915 8). In the July 1922 Kodakery the article accentuates that the particular types of story-telling pictures its author wished to endorse 'are those that portray the everyday incidents in the life of people' ('Story Telling Pictures' 1922 4). The ideas of memory loss and one's unfamiliarity with their own self might have been convincing enough to motivate some camerists to snap away. Yet, based on the information given to the reader in this Kodakery article, many others found the production of mere photographic likenesses sufficient for their needs.

Although Kodak also distributed marketing materials in support of the production of traditional family portraits, the company need not have convinced families of their value. But, in promoting the use of photography in daily life, Kodak strove to persuade the public that recording physical likenesses was not photography's sole purpose. Indeed, the Kodakery repeatedly portrayed common everyday life occurrences as most appropriate for the production of photographic images, emphasising that story-telling pictures are the most valuable of photographs. Even in the 1929 announcement of the prestigious \$30,000 Eastman Prize Contest, the Kodakery editors highlighted that, 'while many subjects are covered in the award classifications [...] the storytelling picture always has universal appeal’ ('\$30,000 Eastman Prize Contest’2). The announcement also directed readers to an article by Robert $T$. Lowell in the same issue, where they could learn once again 'just what is meant by story-telling pictures’ ( $\$ 30,000$ Eastman Prize Contest' 2). On balance, the human face itself does not change noticeably from one day to another. In the early twentieth century as today it was sufficient to record one's likeness in a photograph only every once in a while. But, leaving customers to practice photography that way would have not helped Kodak to illustrate the snapshot photograph's alleged ability to encapsulate memories, thus neither to increase the company's sales.

Yet a closer examination of the Kodakery reveals a paradox: whereas the magazine aimed to train readers to see snapshots as memory capsules, it also guided them to render this particular alleged property evidential by staging their snapshots. In the Kodakery of August 1915, for example, one article concluded with the diktat: 'Bear this in mind $[\ldots]$ conscious posing takes away the story telling reality of the picture' ('Pictorial Interest' 21). The article 'Don't Look at the Camera!', published over a decade later, warned that when the photographed subject looks directly at the lens 'it often accents the appearance of self-consciousness', hence, 'The picture cannot seem to have happened (15). But, whereas conscious posing may compromise the image's unguarded realism, it did not mean that posing for a photograph should be avoided altogether. Explaining that the photograph's ability to tell stories depends on capturing the subjects when they appear to be unaware of the camera's presence, one article emphasised that, 'There may be qualities that come with unconsciousness that are invaluable, but if you are fortunate in your subjects, that is, if your subjects are not too self-conscious, much may be done with co-operation' ('Story-Telling Pictures' 1915 8-9).

Other Kodakery issues delineated strategies that camerists could employ in such circumstances, to render staged photographic scenes into spontaneous moments. In December 1915, an article discussing story-telling pictures of groups of people made the suggestion that camerists ought to allow their subjects to assume comfortable positions before composing the image in the viewfinder. 'Make the exposure, without announcing that you are ready to do so', emphasised the author, 'at the instant the subjects become interested in something other than the photographer 
and the camera' ('Story-Telling Group' 9-10). A later article stressed that 'Even if the subject tries to "pose" for a story telling picture, the evidence of the posing will disappear as soon as the attention of the subject is concentrated on the work or play that constitutes the motif for the picture' ('Story Telling Pictures' 1922 8). The idea that working with the photographic subject could transform staged moments into credible-looking impressions of spontaneity was also advocated by Robert T. Lowell. In the article Lowell published in association with the $\$ 30,000$ Eastman Prize Contest of 1929, he argued that it does not matter how one captures images as long as the results convince viewers of their impartiality:

Making a picture tell a story is by no means difficult. It may require just a little thought on your part and some co-operation from your subjects, though there will be times when you can 'catch' your subjects unaware and in an unposed story-telling situation. Then you will have made an honest-to-goodness story-telling picture. ('Story-Telling' 13)

Not only do such articles seem to have motivated their readers to blur the cognitive boundaries between picture-taking and picture-making, but they also embedded photographic activity into everyday life, turning it into an unremarkable, quotidian experience. The Kodakery framed snapshooting as an activity that generates new objective realities, realities that instantly become absorbed into the camerists and their subjects' lived experiences as authentic occurrences. Nevertheless, Kodakery articles emphasised that concealing the photographer through compliance with the aesthetic of realism - the objectification of the moments captured by the camera-is a prime condition for the successful transformation of staged spontaneity into biographical narratives. Images in which the subjects registered the presence of the camera (and the camerist) veered into conscious self-representation and could not, then, be regarded as spontaneous revelations of the subject's self.

An article by Lawrence Morton from 1926 supports this observation. Morton intended to provide readers with a set of strategies that could assist them in capturing their photographed subjects' natural expressions. 'Natural expressions', clarified Morton, 'are part of the biography the camera may tell. You who make the picture may enjoy made expressions but, in my opinion, you will most enjoy afterward the records of expressions that have actually happened' (9). Morton further argued that capturing genuine facial expressions would attest to the actuality of the experiences shown by the picture, which would thereby enhance the biographical value of the image. Paradoxically, Morton did not advise camerists to wait for authentic facial expressions to surface independently. Instead, he called upon the Kodakery readers to make them happen. ' $[\mathrm{t}$ t is always a good plan to "start something" that will bring out the real feeling', asserted Morton (6). Rather than asking the subjects to attempt believable expressions associated with inner feelings, he argued that ' $[\mathrm{t}]$ he better way would be to create a surprise or to spring something amusing, because real feelings have a way of making real signs' (8). Simply put, Morton encouraged camerists to stage their snapshots through contrived stimuli, alerting them that ' $[\mathrm{t}]$ he camera is a kind of Sherlock Holmes detective. It can't be fooled. It is a great detector of counterfeits' (8). Eliciting situations and only then taking a picture would, according to Morton, guarantee its perception as a credible biographical record.

Kodak popularised the concept of the story-telling picture to secure a public perception of photographs as visual devices that can actually disclose the lived experiences of those they feature, assuring camerists that all experiences, no matter how ordinary, are of universal interest. It used the Kodakery to explicate what visual elements may encourage the viewer to see photographs as encapsulated realities in action, and what visual signs assist pictures to appear as spontaneous, unmediated reflections of reality itself. In this sense, Kodak furnished its 
customers with the ability to manufacture unbiased-looking images, omit any trace of the camera operator in their photographs, and render invisible the process of mediation involved in picture taking.

\section{Pictorial Lives}

In 1914 Kodak launched the Autographic Kodak camera, which enabled users to add some short hand-written inscriptions on the margins of each exposure, immediately after it was made (Coe 104-5). Kodak did not intend that such inscriptions appear in the final prints, although this was also an option. Either way, it suggested camerists use the new feature to preserve brief informative details about the sights recorded. Kodak's manufacture of a camera with a special feature designed for inscribing word-based reminders may seem at odds with the marketing campaign which defined snapshot photographs as replacements for words and memory. However, as West proposes, Kodak's advertisements of the autographic feature pitched it as a means to increase the photograph's authenticity through the inclusion of the camerist's personal handwriting (167). West's observation remains pertinent when considering the Autographic Kodak's advertisements, and some Kodakery articles featured other strategies that the company exploited to subject the written word to photographic images rather than vice versa. ${ }^{7}$

Nevertheless, the photograph's ambiguous relationship with the reality it shows, as well as the photograph's lack of verbal information, were raised as a matter of concern. ${ }^{8}$

Although Kodak promoted the idea that photographs can retain visual information and memories better than the human mind, as well as preserve the camerists' lived experiences better than any other media, it also advocated the use of devices such as brief captions and longer forms of annotation to enhance the narrative potential of images. But the Kodakery presented the use of words alongside photographic images as a mere suggestion that could, for example, make letters, postcards and albums more interesting or simply assist in organising negatives; in its explicit discussions of the relationship between photographs and lived experience, Kodak promoted the use of other, non-textual devices to inculcate an understanding of photographs as biographical narratives.

In March 1915 the Kodakery published the story of the fictional characters Mr. and Mrs. Briggs, who have bought a camera to take vacation snapshots. When the Briggs received their holiday snapshot prints, Mrs. Briggs placed them in an album that she presents to her husband. 'Like the way you've got 'em arranged', Mr. Briggs says approvingly while turning the album pages: 'You've started right off with the snap-shot of me with the luggage, and then there's the old stage that took us over to the camp, and here's the camp, itself, and here's you clearing up the place' ('A Vacation While You Wait' 6-8). Mr. Briggs proclaims, 'It does bring it all back, doesn't it?', to which Mrs. Briggs replies enthusiastically, 'It's just like living your vacation over again' (8). Similar to the story of the Briggs, other Kodakery fictional narratives often focused on the virtues of albums, and explained in great detail what kinds of photographs fellow camerists place in them, how many per page, and in what particular order. At other times, a more didactic tone was struck, with instructional articles to disseminate the same information. However, whether in the form of fiction or advice, the suggestion that photograph albums need to communicate the ways in which individuals change and develop over time appeared repeatedly, complementing Kodak's marketing claim that photographs can be read as biographical narratives. 
The understanding of albums as metaphors for life predated the invention of photography and persisted throughout the nineteenth century. Although photographs of individuals were collated in albums already in the early second half of that century, album compilers treated them primarily as pictorial records of likeness. They often kept photographs in albums to illustrate genealogies, or accompany written descriptions of occurrences that involved the sitters but did not relate to the moments or spaces that their photographs presented (Siegel 116-23).

Photographs, in other words, had not become wedded to the notion of lived experience without Kodak's assistance. The Kodakery of February 1916, for example, introduced to readers an idea allegedly thought of by a fellow snapshot enthusiast. 'I am travelling over nearly all the States', he is said to have explained in a letter to the Kodakery editors, 'and in lieu of a diary I keep my Vest Pocket Kodak constantly loaded with me-each day taking one or two exposures as a record of that day' ('A Pictorial Diary' 21). The album he compiled over the past year contained 365 prints, showing 'a very interesting pictorial record of my travels' (22). Even though, or perhaps because, condensing an entire day into a single, representative image might be challenging, in this article too Kodak recommended that camerists use albums as a way of rendering individual images into a visual narrative of their lives. ${ }^{9}$ Doing so, the author asserted, could in due course serve the purpose of telling 'the history of individuals or communities' (22), and an article from 1926 reminded readers that loose prints inhibit the ability of photographs to communicate coherent narratives, 'because they are seldom looked at in proper sequence' (Davis 18).

The integration of certain types of photographic images into albums, alongside story-telling snapshots, was another common recommendation that the Kodakery articles made in order to assist camerists in enhancing their collections' nonverbal narrative potential. In November 1922 Cartoonist Bradford gave readers some examples of domestic photographs that they may wish to take for this purpose: ${ }^{10}$

The little nooks and cosy places, the little details - the newly post on the staircase, the old clock that 'bongs' out the passing hours, the cat, contentedly purring on the rug, these, and a hundred little things, each a little guide post to the character of the household, that make plain reading to the observer and student of human nature-these, too are 'home' and no photographic chronicle — no album of home pictures - really is complete without them [...] To one who uses just ordinary observation, a little detail like this speaks a language as intelligible as actual speech $[\ldots](10)$

In another article, Merle T. Richards listed some more domestic objects that could be photographed for inclusion in albums, concluding that intimate pictures of these types 'go to make up a real pictorial history of the home' (8). Similarly, photographs of human-made and 'natural' landscapes were pronounced by the Kodakery as a necessary backdrop for establishing the location of the narrative and its mood. By extension, Kodakery articles suggested that the incorporation of such visual records into albums enhance the realistic qualities of story-telling pictures, further engrossing their viewers in the narrative.

Traditionally, however, no biographical account can be considered complete without immersing the reader in the unremitting development of its protagonist's life story, character and characteristics (Barros 1-18; Brockmeier; Wang). Indeed, the Kodakery of February 1920 addressed the idea that the production of effective photographic biographical accounts necessitates the recording of the subject's physical change and personality development over time. In an article entitled 'Making a Kodak Biography', Albert Crane Wallace argued that taking photographs of babies month by month, and later year by year, would show the child in subsequent viewing as if she or he were growing up before the viewers' eyes. Pictures of a boy 
and girl at different stages over a period of a couple of years followed the article to illustrate this point.

The Kodakery of August 1922 also advised readers to record their children's physical development at regular intervals, beyond infancy. The issue featured the story of the Phillips' family holiday under the title 'The Flower of the Family in the Wheat Field'. On one of the Philips' family vacations at Uncle Joe's farm, Uncle Joe presented them with an album that included pictures taken during the family's vacation at the same farm two years earlier. One depicted the family's daughter, Mary, in Uncle Joe's wheat field. 'Maybe we ought to go down there and look at it', proposed Uncle Joe (24). Once the Philips arrived at the wheat field, Mary pleaded with Uncle Joe to take her picture again. The family posed Mary in the wheat, the same way as two years earlier. ' $[$ t hardly comes to Mary's shoulders now and two years ago it was right up around her neck, according to that picture we just looked at', remarked Uncle Joe (25). But Mary was only 10 years old when her previous picture was taken, Mary's mother explained, adding that Mary had grown almost a foot since then. Therefore, the Philips agreed that Mary should pose in the wheat field for a new picture every year at harvest time, 'to measure Mary's growth by the wheat' (25).

In February 1929, Robert T. Lowell introduced photographic records of individuals' physical growth in association with the ability of photographs to portray personality development. Using a selection of photographic images as illustrations for his argument, Lowell demonstrated how inserting into an album photographs of the same person taken over years can provide a unique pictorial narrative, tracing the emancipation of subjects from infants into independent adults. The photograph chosen to illustrate the article's first page shows a woman sitting next to a baby in a nursery bed; the caption counsels readers to 'Start the picture story early' (Lowell 'Birthday' 18). Another photograph shows the portrait of a young woman, posed outdoors and smiling at the viewer. "They soon "shoot up", reads the caption, as if to clarify why it is imperative to "Start the picture story early' (18). Discussing how he and his partner have used their camera to keep records of their children's personality and physical development, Lowell explained that, 'While we make pictures frequently of these two, there are certain high spots in the album [...] Since the start we have religiously kept a pictorial record of the birthdays' (20). One of the photographs chosen to illustrate this part of the article shows a woman standing next to a boy by the window, with a stick over his head. 'How tall on his fourth birthday?', asks the caption, implying that this ritual should be re-enacted annually (19). Finally, on the article's last page there are two other photographs. Accompanied by the caption 'A "no hit" pitcher', one of them shows a young boy playing baseball (21). The other features two boys engaged in paramilitary activity of some description, under the caption 'Scout age' (21).

A number of Kodakery articles also presented the option of creating photographic sequences to describe short life-incidents, moment-by-moment, arguing that camerists could marshal this visual strategy to narrate through images alone. ${ }^{11}$ But, it is yet another short story that demonstrates Kodak's efforts to encourage the use of multiple images in sequence, to make coherent biographical narratives. Written by Paul Griffin Lee for the Kodakery of November 1926, it tells the tale of Ted, a three-year-old child, and his father's preparation for the Christmas season (12-14). Considering what gift might most please Ted's grandmother, his father suggests they place Ted's photographs in an album, from birth to the present. In this fictional narrative, Lee reminds readers to leave a large number of blank pages for pictorial descriptions of the child's evolution, yet to be taken (14). 
A large number of Kodakery authors circulated ideas similar to Bradford's, Richards', Wallace's, Lowell's, and Lee's, to remind the readers of the snapshot photograph's unbreakable connection to the human condition of being and becoming. Kodak recognised that framing photographs as coherent biographies required methods to emphasise continuity and atmosphere, and it was to that end that the Kodakery advised camerists to collate their story-telling pictures into albums, arrange them in a progressive order, and include accompanying scenic or location images.

\section{Kodak's Photographic Biography}

Kodak knew all too well that by themselves pictures cannot explain what they display, visualise the experience of life, nor turn it into a coherent, credible pictorial narrative. But, the company helped to make photographs synonymous with biography by establishing a public discourse that framed the camera as an autonomous, one-eyed witness, and portrayed the occasion of picture taking as a routine activity in the photographable spectrum of lived experience. It equipped its customers with the set of skills necessary for transforming mundane occurrences into compelling sights, rendering subjectively constructed moments into spontaneous realities, and turning discontinuous incidents into short narratives. The advice that Kodak disseminated through the Kodakery, coupled with the illustrations the magazine featured, proliferated the idea that photographs must be produced and looked at as objective surrogates of both the changing human body and individual subjects' lived experiences in time and space.

That the relationship between photography and biography needed to be explained repeatedly, and often by words, suggests that the link between the two was by no means taken for granted. Since the first half of the twentieth century, however, snapshots have turned out to be the most ubiquitous of all photographic images (Chalfen 4-48; Sarvas and Frohlich 1). Snapshooting and becoming the subject of snapshots have become commonplace occurrences and, as West argues, the meanings often associated with snapshots today mirror Kodak's vision of photography. ${ }^{12}$ Explaining that the status of the snapshot as a commodity is 'unique in that it maintains an aura of simplicity whose meaning derives in part from the illusion that the snapshot-unlike most other commodities - is made by its users', West further clarifies that snapshot photography 'thrives on codes of "simplicity" as a means of shaping perceptions of experience' (7).

Focusing on the ways in which Kodak contributed to developing a perception of photographs as interchangeable with biographical accounts, this essay has shown how the company established a common visual vocabulary and set of photographic practices to facilitate this process. Although it focused on Kodak, the essay asks us to attend to the role played by the photographic industry in shaping photography natives' attitudes towards photographic images and practices. If photographs can divulge any biographical details about their sitters, viewers, users, or producers, they must also be seen as fractured representations of the photographic industry's complex biography at large. This biography has been masked by the attitudes to photography that this very industry has gradually instilled in the public domain since George Eastman launched the first Kodak camera in 1888. Yet, unpacking the role the photographic industry has played in the development of popular attitudes towards photography may help scholars gain a more nuanced understanding of the ways in which photography and life-writing practices have shaped each other at least since the twentieth century. 


\section{References}

“\$30,000 Eastman Prize Contest Ends May 31, 1929! Still Time to Win Big Cash Awards.” Kodakery: A Magazine for Amateur Photographers May 1929: 2-4.

Adams, Timothy Dow. Light Writing and Life Writing: Photography in Autobiography. Chapel Hill: U of North Carolina P, 1999.

“The Autographic Kodaks.” Kodakery: A Magazine for Amateur Photographers Nov. 1914: 3-8.

Barros, Carolyn A. Autobiography: Narrative of Transformation. Michigan: U of Michigan P, 2001.

"Because this is the First Number." Kodakery: A Magazine for Amateur Photographers September 1913: 3.

Bradford, Cartoonist (Walter R. Bradford). "Home Pictures that are Different." Kodakery: $A$ Magazine for Amateur Photographers Nov. 1922: 10-4.

Brockmeier, Jens. “Autobiographical Time.” Narrative Inquiry 10.1 (2000): 51-73. doi: 10.1075/ni.10.1.03bro

Chalfen, Richard. Snapshot Versions of Life. Bowling Green: Bowling Green State U Popular P, 1987.

Coe, Brian. Cameras: From Daguerreotypes to Instant Pictures. Gothenburg, Swed.: Nordbok, 1978.

Davis, W. S. "Vacation Picture Books." Kodakery: A Magazine for Amateur Photographers Oct. 1926: $18-20$.

“Don't Look at the Camera!.” Kodakery: A Magazine for Amateur Photographers May 1926: 15.

"The Flower of the Family in the Wheat Field." Kodakery: A Magazine for Amateur Photographers Aug. 1922: 24-25.

Gernsheim, Helmut, and Alison Gernsheim. The History of Photography. London: Thames, 1969.

Hurter, Bill. Family Portrait Photography. Buffalo, NY: Amherst, 2006.

"The Kid and the Cop: A Kodak Story that Really Doesn't Need These Few Words." Kodakery: A Magazine for Amateur Photographers July 1917: 14-15.

King, Barry. "Photo-Consumerism and Mnemonic Labor: Capturing the 'Kodak Moment'." Afterimage 21.2 (1993): 9-13.

Lee, Paul Griffin. "The Greatest Christmas Card Ever Sent: At Least Grandmother Thought So." Kodakery: A Magazine for Amateur Photographers Nov. 1926: 12-14.

"A Little Cousin of the Post Card." Kodakery: A Magazine for Amateur Photographers Nov. 1914: 19_ 21. 
Lowell, Robert T. "Birthday Pictures." Kodakery: A Magazine for Amateur Photographers Feb. 1929: $18-21$.

Lowell, Robert T. "Story-Telling Pictures: What They Are and How to Make Them." Kodakery: A Magazine for Amateur Photographers May 1929: 11-14.

Morton, Lawrence. "Expression.” Kodakery: A Magazine for Amateur Photographers Nov. 1926: 211.

Musello, Christopher. "Family Photography." Images of Information: Still Photography in the Social Sciences. Ed. Jon Wagner. Beverly Hills: SAGE, 1979. 101-18.

"Musings of the Kodak Philosopher." Kodakery: A Magazine for Amateur Photographers July 1915: $3-5$.

“A Pictorial Diary.” Kodakery: A Magazine for Amateur Photographers Feb. 1916: 21-22.

"Pictorial Interest." Kodakery: A Magąine for Amateur Photographers Aug. 1915: 20-21.

“The Pictorial Letter.” Kodakery: A Magazine for Amateur Photographers June 1926: 22-23.

"Picture Records_-True to Life." Kodakery: A Magazine for Amateur Photographers Nov. 1915: 6.

Richards, Merle T. "Unusual Pictures about the Home." Kodakery: A Magazine for Amateur Photographers Feb. 1929: 3-10.

Rose, Gillian. Doing Family Photography: The Domestic, the Public and the Politics of Sentiment. Farnham: Ashgate, 2010.

Rugg, Linda Haverty. Picturing Ourselves: Photography and Autobiography. Chicago: U of Chicago P, 1997.

Sartore, Joel, and John Healey. Photographing Your Family. Washington, DC: National Geographic, 2008.

Sarvas, Risto, and David Frohlich. From Snapshots to Social Media-The Changing Picture of Domestic Photography. London: Springer, 2011.

"The School Bell.” Kodakery: A Magazine for Amateur Photographers Oct. 1923: 3-4.

Siegel, Elizabeth. Galleries of Friendship and Fame: A History of Nineteenth-Century American Photograph Albums. New Haven: Yale UP, 2010.

Slater, Don. "Consuming Kodak." Family Snaps: The Meaning of Domestic Photography. Eds. Jo Spence and Patricia Holland. London: Virago, 1991. 49-59.

Slater, Don. "Domestic Photography and Digital Culture." The Photographic Image in Digital Culture. Ed. Martin Lister. London: Routledge, 1995. 129-46. 
Slater, Don. "Marketing Mass Photography." Visual Culture: The Reader. Eds. Jessica Evans and Stuart Hall. London: SAGE, 1999. 289-306.

"Story-Telling Group.” Kodakery: A Magazine for Amateur Photographers Dec. 1915: 8-10.

“Story-Telling Pictures.” Kodakery: A Magazine for Amateur Photographers Nov. 1915: 7-10.

“Story Telling Pictures.” Kodakery: A Magazine for Amateur Photographers July 1922: 2-9.

Stotesbury, John A. "Snapshot Lives: Kodak Culture and South African Autobiographical Narratives of the Self.” Scrutiny2 5.2 (2000): 24-32. doi: 10.1080/18125440008565966

Taylor, Maureen A. Preserving Your Family Photographs: How to Organize, Present, and Restore Precious Family Images. Cincinnati: Betterway, 2001.

“To Our Readers.” Kodakery: A Magazine for Amateur Photographers June 1915: 25.

“A Vacation While You Wait.” Kodakery: A Magazine for Amateur Photographers Mar. 1915: 3-8.

Volpe, Andrea. "Cartes de Visite Portrait Photographs and the Culture of Class Formation." The Middling Sorts: Explorations in the History of the American Middle Class. Eds. Burton J. Bledstein and Robert D. Johnston. New York: Routledge, 2001. 157-69.

Wallace, Albert Crane. "Making a Kodak Biography." Kodakery: A Magazine for Amateur Photographers Feb. 1920: 15.

Wang, Qi. The Autobiographical Self in Time and Culture. Oxford: Oxford UP, 2013.

West, Nancy Martha. Kodak and the Lens of Nostalgia. Charlottesville: UP of Virginia, 2000.

\section{Notes}

\footnotetext{
${ }^{1}$ See, for example, Hurter 13; Sartore and Healey 163; Taylor 5.

2 See, for example, Adams; Rugg; Stotesbury.

${ }^{3}$ By 'photography natives' I refer to individuals for whom photography had already been an integral part of life.

${ }^{4}$ For a discussion of the restrictive representational conventions that dominated popular photo-portraiture in nineteenth-century American photography studios, see, Volpe.

${ }^{5}$ Although Kodak printed other substantial publications, owing to the length of this article I have chosen to focus on the Kodakery as it was the company's longest-lasting magazine. In addition, its visual and textual contents often mirrored the information that Kodak conveyed to non-professional camera users in its other publications.

${ }^{6}$ Otherwise, in average the company offered annual subscriptions for only 60 US cents, two years for one US dollar.

${ }^{7}$ See, for example, 'A Little Cousin of the Post Card'.

8 See, for example, 'The Autographic Kodaks'; 'The Pictorial Letter'.

${ }^{9}$ Cf. West 177.

${ }^{10}$ Cartoonist Bradford was the nom de plume used by the popular American cartoonist and author Walter R.

Bradford in his numerous contributions to the Kodakery.

${ }^{11}$ See, for example, 'Story-Telling Pictures' 1915; 'The Kid and the Cop'.

12 See also, Rose (25-40).
} 